This item was submitted to Loughborough's Research Repository by the author.

Items in Figshare are protected by copyright, with all rights reserved, unless otherwise indicated.

\title{
Communities in university mathematics
}

PLEASE CITE THE PUBLISHED VERSION

http://dx.doi.org/10.1080/14794802.2014.918351

\section{PUBLISHER}

Taylor and Francis / @ British Society for Research into Learning Mathematics

\section{VERSION}

SMUR (Submitted Manuscript Under Review)

\section{PUBLISHER STATEMENT}

This work is made available according to the conditions of the Creative Commons Attribution-NonCommercialNoDerivatives 4.0 International (CC BY-NC-ND 4.0) licence. Full details of this licence are available at: https://creativecommons.org/licenses/by-nc-nd/4.0/

\section{LICENCE}

CC BY-NC-ND 4.0

\section{REPOSITORY RECORD}

Biza, Irene, Barbara Jaworski, and Kirsti Hemmi. 2019. "Communities in University Mathematics”. figshare. https://hdl.handle.net/2134/18197. 
(Special Issue: University Mathematics Education)

\section{Communities in University Mathematics}

Irene Biza ${ }^{a}$, Barbara Jaworski ${ }^{b}$, Kirsti Hemmi ${ }^{c}$

${ }^{a}$ University of East Anglia, Norwich, UK

${ }^{b}$ Loughborough University, Loughborough, UK

c Mälardalen University, Västerås, Sweden

Correspondence details:

Irene Biza, School of Education and Lifelong Learning, LSB-1.30, University of East Anglia, NR4 7TJ, Norwich, UK, i.biza@uea.ac.uk 


\section{(Special Issue: University Mathematics Education)}

\section{Communities in University Mathematics}

This paper regards communities of learners and teachers that are formed, develop and interact in university mathematics environments through the theoretical lenses of the work of Lave and Wenger (1991) and Wenger (1998) on the Community of Practice. In this perspective learning is drawn on the participation in a community. In addition, when inquiry is considered as a fundamental way of participation, the community becomes a Community of Inquiry. The theoretical underpinnings of the above approaches with examples of their application in research in university mathematics education are discussed in the sections of this paper. The paper concludes with a critical reflection on the theorising of the role of communities at university level teaching and learning as well as ways forward for future research.

Keywords: community of practice; community of inquiry; legitimate peripheral participation; identity, critical alignment, university mathematics education

\section{Introduction}

Experience in university mathematics teaching indicates that there is no clear consensus between university teachers ${ }^{1}$ and students on the meaning and the value of mathematics (e.g. Solomon, 2006). This observation attracted the interest of mathematics education researchers to investigate the takes on the meaning and values of mathematics in different communities - such as researcher mathematicians, teachers of mathematics, undergraduate and postgraduate students - that are involved in practices within university especially in relation to the teaching and learning (e.g., Burton, 2004; Herzig, 2002; Solomon, 2007). In this endeavour, research has been drawn on the theoretical

\footnotetext{
${ }^{1}$ We use (university) teacher to describe all those involved in the teaching of mathematics at university level. We describe other identities with specific characterisations, such as researcher mathematician or mathematics educator, when it is necessary.
} 
construct of the Community of Practice (henceforth, CoP) based on the work of Lave and Wenger (1991) and Wenger (1998) and the Community of Inquiry (henceforth, CoI Particularly within an developmental environment and based on the work of Jaworski, Goodchild, and many others (e.g., Goodchild, Fuglestad and Jaworski, 2013).

Our aim in this paper is to stress and give more insight into the theorisation of the role of these communities in the learning and teaching of mathematics at university level and to take this theorisation forward in future research. Our point is that mathematical practices at university level are distinguished from those at secondary or primary level for reasons related to the mathematical content, the teachers and the students involved. At university level the mathematical theory becomes a language of communication with very specific and rigorous rules and processes (such as theorems, definitions and proofs). Teachers who are very often researchers of mathematics become learners themselves and experience the double identity of the teacher and the researcher in the same institutional environment. Students are adults who are accountable for their choices, belong to multiple communities, often have to learn individually and may consider their studies as a step towards their professional development.

In the following sections we present the main theoretical underpinnings of the CoP and CoI and we exemplify how their theoretical constructs have been used in university mathematics education research in indicative studies as well as in more detailed presentation of two research cases. We conclude the paper with a discussion on the potentialities, limitation and ways forward of $\mathrm{CoP}$ and $\mathrm{CoI}$ application into research, also in (dis)connection with other sociocultural theories of university mathematics.

\section{Theoretical perspective}

In taking a perspective on knowledge, learning and teaching within university 
mathematics we start from the position of Vygotsky that cognition arises through participation in sociocultural contexts (Vygotsky, 1978). We see learning to take place through interactions in social settings, specifically within the communities in which university students, their teachers, research students and researchers interact. A community is a group of people identifiable by who they are in terms of how they relate to each other, their common activities and ways of thinking, beliefs and values. Such communities of course extend beyond the university boundaries and into wider cultures and systems of which the people are a part. In taking a community perspective, we are focusing on specific practices within a university, especially those that include the teaching and learning of mathematics. We draw specifically on the work of Lave and Wenger (1991) and Wenger (1998) who introduced the idea of Communities of Practice $(\mathrm{CoP})$ and we extend their theory to the university learning and teaching of mathematics.

These two principal sources take different positions on a community of practice and its constitution. Lave and Wenger focus on the concept of Legitimate Peripheral Participation (LPP) by which newcomers to a practice are drawn into the practice, becoming ultimately old-timers, around whom the practice is based. The transition from newcomer to old-timer involves differing trajectories of identity. Kanes and Lerman (2008) characterise such transition as the active process of an individual who wants to move from the periphery to the centre. Wenger (1998), on the other hand, focuses on the community as a whole and the practice that take place in it: "The concept of practice connotes doing, but not just doing in and of itself. It is doing in a historical and social context that gives structure and meaning to what we do. In this sense practice is always social practice” (p. 47). We recognise the long history of the practices of mathematics, learning of mathematics and research into mathematics that has led to where we are 
today and which is ever present in the 'doing' in which we engage at university level. According to Wenger (1998) identities form trajectories, both within and across communities of practice, including the inbound trajectories (pp. 154) from the periphery to the centre. Also, trajectory can be seen as a continuous motion that connects the past, the present and the future. Kanes and Lerman (2008) describe Wenger’s (1998) perspective as passive and inductive, and we acknowledge that Wenger (1998) does not put so much attention on how trajectories are influenced and operationalized in the context of the community.

Within a CoP, Wenger (1998, p. 55) introduces two key processes through which people make meanings (through which they learn): participation and reification. Participation involves being within a CoP, taking part in its activities, interacting, negotiating, agreeing, disagreeing, formulating and making sense. The last two of these, formulating and making sense link participation to reification. Reification means “making into a thing ... the process of giving form to our experience by producing objects that congeal this experience into thingness" (p. 58). Wenger states, "We project our meanings onto the world and then we perceive them as existing in the world, as having a reality of their own” (p. 58). This has particular resonance with mathematics in which abstract entities and relationships are formed through negotiation in mathematical communities and over time take on a nature of objects in mathematics. In conceptualizing CoP, Wenger talks of three dimensions of practice: mutual engagement - establishing norms, expectations, ways of working and social relationships, joint enterprise - developing common understandings of what the enterprise is about and where it is going, its aims and ideals; and shared repertoire - the objects that we use and how we use them, resources such as technology, symbols, abstract forms. We can see these dimensions encompassing lectures and lecturing, definitions and theorems, 
symbolisation and proof, graphing and the technology of graphing, mathematical software and so on. These dimensions help us to characterise and analyse our practice. We need also to interpret our various roles as practitioners within our practice - how do we define ourselves, and are there differences between groups such as researchers, teachers, students, graduate students? Wenger talks of learning as “a process of becoming” (p.215). This, he claims, is “an experience of identity” (p.215), where identity "serves as a pivot between the social and the individual, so that each can be talked about in terms of the other” (p. 145). He offers again three dimensions which he calls this time "modes of belonging” in which identity is conceptualised in terms of "belonging” to a community of practice involving “engagement”, “imagination” and “alignment” (p. 173). Any individual engages with practice, alongside co-practitioners, uses imagination to weave a personal trajectory within the practice and aligns with the norms and expectations of the practice. Thus individual identity is defined in relation to the individual's (non-)participation in the CoP and of course other CoPs to which the individual belongs.

In a following section, we offer case studies of university practice in which theory of CoP has been used to make sense of characteristics and issues. This will draw on Lave and Wenger and Wenger's constructs within a broad perspective of individual meanings developing through social practice. However, before doing so, we will address what we see as being a limitation of Wenger's CoP theory when it comes to characterisation of a process of developing practice and learning from research which identifies characteristics and issues.

The mode of belonging designated as "alignment" describes ways in which the person-in-practice 'lines up with' the norms and expectations that hold sway within the CoP. This can be seen to perpetuate/sustain forms of practice whether or not they are 
the best for achieving the goals of practice (Jaworski, 2008). There is a scepticism and sometimes critique on certain traditional practices (e.g., chalk and talk, lecturing style) as effective teaching methods for students’ learning (Biggs, 2003). Students experience mathematics as something 'done to them' rather than 'done by them'; and do not share in the ownership of meaning, let alone meaning making — they are excluded from vital aspects of participation (Solomon, 2007, p. 90). Thus, alignment with traditional practices can leave something to be desired in relation to students' understanding of mathematical concepts.

In most practices, alignment of some kind is unavoidable; however, it does not have to be uncritical. A critical alignment would imply a questioning of the status quo. For example, the teacher who recognises that students are suffering serious problems with the traditional mode of lecturing might seek to modify her practice to support the students in some way. Asking questions about one's practice is a form of 'inquiry', inquiring into the teaching-learning process to achieve 'better' outcomes from it, taking an inquiry stance in practice; inquiry develops as a way of being for the teachers (and students) involved (Cochran-Smith \& Lytle, 1999; Jaworski, 2004; Wells, 1999). Thus we might say that teacher and students working together in inquiry ways form a “community of inquiry”.

Wells (1999, p. 122) writes, "inquiry does not refer to a method ... still less to a generic set of procedures for carrying out activities. Rather it indicates a stance towards experiences and ideas - a willingness to wonder, to ask questions and to seek to understand by collaborating with others in the attempt to make answers to them”. Inquiry is also fundamental in all research processes (Stenhouse, 1984), so research which seeks to promote the development of mathematics teaching, as well as to document its characteristics and issues, is a process of systematic inquiry. Such inquiry 
has resonance too with the use of inquiry-based tasks to engage students with mathematics and foster concept formation (Abdulwahed, Jaworski and Crawford, 2012).

The idea of inquiry community can be seen to transform the idea of Community of Practice. A Community of Inquiry (CoI) is a $\mathrm{CoP}$ in which inquiry is a fundamental way of being in practice. So the CoI encompasses Wenger's three dimensions: mutual engagement is an inquiry-based process; joint enterprise involves the goals of inquiry which are to reach better understanding of what is being questioned; shared repertoire includes such resources as inquiry-based tasks and inquiry approaches in exploring mathematical concepts. Identities of participants within a CoI develop through trajectories of engagement and imagination as for a CoP; however, the crucial difference is with alignment. In a CoI, alignment is always critical alignment. As a 'normal' part of their participation, participants question the practices in which they engage. Such questioning leads to new forms of practice and new awarenesses of the problems and issues in developing effective ways of working and good outcomes for students learning.

The ideas of CoP and CoI are exemplified in relation to the research studies discussed in the next two sections.

\section{Communities of practice in the university mathematics}

Research in university mathematics education has used the CoP and CoI theoretical concepts in order to get some insight on how learners, teachers and researchers act and interact in specific institutional and sociocultural contexts. In order to gain some understanding on how $\mathrm{CoP}$ or $\mathrm{CoI}$ is conceptualised in research and how and in what extent the relevant concepts have been applied as analytical tools, we conducted a literature review on studies on university mathematics practices that consider these 
practices to be embedded in a community activity. Indicative cases from this review are presented in this section.

In studies conducted by Solomon and colleagues in the English undergraduate mathematics context, students participate in the general undergraduate student community, the mathematics undergraduate community and the first-year student community within each of the above communities. Additionally students belong to the classroom community of learners and tutors. These communities are different from the community of researcher mathematicians of which students may not be aware or of which they do not aspire to be a part (Solomon, 2007). Students' participation (or nonparticipation) in multiple communities of practice and sometimes communities with opposing rules of engagement may result in differential experiences of identity and belonging and generate identities of not belonging among students. For example, students may experience non-participation to the mathematical discipline community of practice - a teaching-learning community of students and teachers - which emphasises deep understanding of mathematical rules and the justification behind these rules. This non-participation can lead students to marginality from the mathematical discipline community of practice. This marginalisation, according to Solomon’s (2007) study, might mean alignment to the rules of the community of undergraduates, which emphasises summative assessment and surface learning. Solomon (2006), also, discusses whether in what extent undergraduate students share the same epistemic values of mathematics with the community of the researcher mathematicians. She mentions that the way undergraduate mathematics is taught and portrayed in the lectures of the English university is disjoint with the practitioner's/lecturer's tacit knowledge and practice in mathematics research. Students are introduced to a predefined structure of definition-theorem-proof that hides research approaches such as intuition, trial and 
error, building and testing conjectures. As a result students develop identities and beliefs about mathematics and learning of mathematics, which are in disagreement with the practices and epistemic values of the mathematics community.

Similarly to the study above, a substantial part of the research on CoPs in university mathematics focuses on proof, an important element in mathematical practices (e.g. Hemmi, 2006, 2008, 2010; Solomon, 2006). In these studies, the introduction to proof and proving processes is embedded - or aims to be embedded - in the process of students' enculturation to the mathematical way of thinking and working as we exemplify in more details in the next section. However, not all the students aim to become mathematicians and, especially in the first year of their studies, do not have access to the mature practices of the experienced mathematicians (Solomon, 2006). Additionally, not all the teachers of mathematics are researchers of mathematics (Biza, 2013; Jaworski \& Matthews, 2011a).

In postgraduate, as opposed to the undergraduate level of mathematics we can assume that students aim at least to be involved in research of mathematics. So, we can see them as legitimate peripheral participants in the community of the researcher mathematicians. For example, in a study conducted in the US by Herzig (2002) on doctoral mathematics students and faculty experiences in the mathematical community of their department, doctoral students encounter two communities: firstly the coursetaking community with the relevant assessment (coursework and examination) and then the research community. Students who become integrated in the first community have little access to mathematical research practices and as a result they are prevented from peripheral participation into what is necessary for their integration later on to the research community. For the faculty, the obstacles to participation are often intentional. They aim to force the students to work hard and prove that they are able to complete 
their doctoral studies before important resources are invested. To students, the lack of opportunities for participation into mathematical research practices is frustrating and interferes with their learning of mathematics.

The main focus of the research examples so far was on the students' role in communities formed in university mathematical practices. If we shift now the focus to the teaching practices, there is not always a consensus on the joint enterprise in mathematical teaching. Jaworski and Matthews (2011a) studied the cases of researcher mathematicians and mathematics educators all lecturing in mathematics in an English mathematics department. The analysis of their discourses where teaching was concerned indicated that the joint enterprise of teaching was hard to be justified. Teachers demonstrated different understandings regarding the meaning and the aim of teaching mathematics. For example, some teachers do not care about students' attendance in lectures and transfer to the students the responsibility of participation whereas for some others lectures provide inspiration and structure to students and want students to attend and gain from this experience. Biza (2013) discussed the existence of multiple communities (researcher mathematicians/statisticians, mathematics educators, users of statistics etc.) practising in the teaching of mathematics and statistics in an English mathematics department and the influence of these communities in the experiences of a new university teacher of statistics. In the last two studies, mathematicians and mathematics educators join each other in the mutual engagement of university mathematics teaching (Biza, 2013; Jaworski \& Matthews, 2011a). What is still questionable is whether they can be considered as legitimate members of the same community or/and if they act as brokers (i.e. members of more than one community) between different communities. Another approach in research sees the new teacher of mathematics as a newcomer who learns from the experienced teachers, the old-timers, 
through their LPP in the community of practice that has already been established in the institution they are entering (Blanton \& Stylianou, 2009).

All the above examples are using the theoretical construct of the CoP with focus either on the trajectory from the periphery to the centre (LPP, Lave and Wenger, 1991) or with emphasis on the community (the practices and the identities, Wenger, 1998). We found only one developmental study that employs the concepts of the Community of Inquiry on engineering students’ conceptual understanding of mathematics (Jaworski \& Matthews, 2011b), which we discuss in more detail in the next section. It is true that there is a substantial body of work on innovative approaches to teaching mathematics in higher education focusing on conceptual understanding and student-centred pedagogies including inquiry based learning. However, the majority of this work reflects idiosyncratic views and/or it draws on constructivists' approaches focusing on individual learning leaving out the complexity of the sociocultural context in which this learning is taking place (Abdulwahed, et al., 2012).

In the next section we present in more detail two characteristic research cases from the aforementioned review that employ a community approach in undergraduate students' understanding of proof (CoP) and in teaching for engineering students conceptual understanding (CoI).

\section{Employing the community approach into research}

\section{Case 1: Proof in the process of entrance to the mathematical community}

In this section, we describe a research application of CoP that combines both Lave and Wenger's (1991) and Wenger’s (1998) positions in a study investigating university teachers' pedagogical perspectives on and students' experiences of mathematical proof at a mathematics department in Sweden (Hemmi, 2006; 2008; 2010). Both qualitative 
and quantitative data were collected consisting of interviews with mathematicians ${ }^{2}$, questionnaires and focus group interviews with students in different levels of their studies, observations of lectures and analysis of examinations and textbooks. In this example, we discuss how the CoP theory shaped the focus of the study and its data analysis. From Wenger’s (1998) perspective on CoP, constructs such as mutual engagement, joint enterprise, shared repertoire, participation/non-participation, identity building, negotiation/ownership of meaning are used to give insight into the mathematical community at the department, the mathematical practice and the role of proof in it, as well as, into participants' positions and engagement in this practice. From Lave and Wenger's perspective on CoP, constructs such as LPP and transparency of mediating artefacts are used to illustrate students' peripheral participation and tensions and conflicts in their trajectories.

"Proof is the soul of mathematics" as a university teacher in the study claimed. Proof is a multi-faceted notion, difficult to define and according to the teachers in the study, it actually permeates all mathematics. From Wenger's CoP perspective, proof is identified as reification and, hence, can refer both to a process of proving and its product reflecting the complex process of working with and creating proofs. The balance between the intuitive and formal aspects and between inductive and deductive modes of reasoning, can be connected to proof as a process of reification and there is an on-going negotiation of meaning along with these interacting aspects of proof, in which both teachers and students participate (Hemmi, 2006, 2008, 2010).

\footnotetext{
${ }^{2}$ In the rest of this research case, we will continue using (university) teacher to describe all those involved in the teaching of mathematics, although all of the teachers in this study would call themselves mathematicians in the first place
} 
The newcomers (students) have to absorb a part of mathematical theory, which come form outside, into their practice. Reifications coming from outside, have to be reappropriated into a local process in order to become meaningful (Wenger, 1998).

From the perspective of Lave and Wenger (1991) proof can be seen as an artefact with several important functions in the mathematical practice (e.g., Weber, 2002; Hanna \& Barbeau, 2008). Lave and Wenger introduce the concept of transparency of the artefacts in connection to technology but in this study it is used for describing proof as a symbolic and intellectual artefact in the teaching and learning of mathematics. The term transparency refers to the way in which using artefacts and understanding their significance interact to the learning process (see Hemmi, 2008).

In this study, all people who are involved in university level mathematics (the practice) at the department are members of the same CoP. The mutual engagement consists of studying, teaching/explaining, learning and communicating mathematics. The learning defines this community and the enhancement of this learning can be seen as the joint enterprise for both teachers and students. Learning is conceived as increasing participation in the community of practice of mathematics which leads to changing identities. All the members of this CoP are engaged in the learning of mathematics in various ways and all of them use partly the same tools, even if the learning of mathematics occurs on very different levels. In this sense researching new mathematics can, also, be seen as learning; since it leads to increasing participation with changing identities and extends the collective knowledge of mathematics (see Hemmi, 2006, p. 34-36). The shared repertoire includes routines like organising courses, seminars and examinations, but, also, words and symbols specific for the mathematical language and criteria for justifying knowledge in mathematics (including proof). 
According to Wenger (1998) one’s identity is always changing and building an identity consists of negotiating meanings of the experiences in social communities. Not only the students but also the teachers constitute a heterogeneous group concerning their identity building as some of them devote more time for research and work with graduate students while others focus more on teaching and the development of undergraduate courses.

Only a small part of the students will become mathematicians but many of them leave the practice after a while and some of them may become brokers between the mathematical practice and some other practices (see Wenger, 1998). Yet, the students need to use the established tools and reifications, like mathematical theories and language with specific symbols and, particularly, get used to a rigorous and systematic way of presenting mathematics with definitions and proofs that are acceptable in the mathematical practice at the university. The process of students' identity forming can be seen through Wenger's terms of participation/non-participation and their interaction.

The analysis shows that the newcomers (students) eventually started to talk about the role of proof in mathematics in a similar manner as the old-timers (teachers) did. The following example shows that some students, already from the first term, associated proof with "real mathematics" and "understanding” in contrast to school mathematics, which was connected to rule learning and applications of formulas without understanding:

I think it's another thing here. In upper secondary school we had a lot of rules, you learn a lot of rules and then you just go ahead. There is nothing to understand. But here it's more like...he [the teacher] stresses it all the time, to count is not mathematics but mathematics is the understanding of it and that is exactly the point. (Student - Basic course, 2004) 
In the above extract, the student has build a meaning that shares old-timers' respects and values - and what was a part of their identity "he [the teacher] stresses it all the time”. In that way, students had the possibility to make the old-timers’ practice their own practice. In particular, after the first assessment on proof in the second term students in the focus groups started to talk about school mathematics as "doing sums and applying formulas”, and university mathematics as proof connected to "questioning the evident”, “derivation of formulas” and "the understanding of mathematics by seeing how everything are related”. These are aspects that also the teachers connected to proof. The students expressing themselves in this manner were considered as developing an identity of participation. In contrast with those students who seemed to be developing an identity of non-participation, these students talk about the advantages of studying proof, for example they state that mathematics becomes easier when one learns proof even if it can be hard to work with proofs.

I think that if you go through the proofs and understand them you get a lot for free, since you can always go back, I mean a proof is often a rather concentrated piece and if you have understood it you hardly have to cram at all. No, I mean that then you don't have to sit with everything else that takes so much time if you want to spare some time. It is clear it can be hard to work through them and really acquaint yourself with them but it can actually be worthwhile (Student - Intermediate course, 2004)

The students who developed an identity of non-participation stopped listening to the teachers when they proved theorems, leaped over the proofs in the textbooks and could not see any meaning in activities involving proofs and proving. They experienced the teachers' proofs during the lectures as obligatory ritual, without any real purpose. I often feel that they have to give the proof whether or not someone understands it, that's how it feels. (Student - Intermediate course, 2004) 
Also they did not see any meaning of studying the proofs as they felt they had no use of them in problem solving or applications.

Most often you don't have to be able to know anything of the proofs in order to solve problems. (S - I, 2004)

Wenger (1998) states that it is the way information can be integrated within an identity of participation that transforms information into knowledge and makes this empowering. The way, in which the students in the previous examples talked shows that the information about proof they got in the lectures did not build up to an identity of participation but remained alien, fragmented and unnegotiable to them (see Hemmi, 2006).

Peripheral participation involves a mix of participation and non-participation where the participation aspect is dominating. The following extract, in which a student talks about her first lectures, indicates that students who manage to accept nonparticipation as an adventure may experience the encounter with proof as a challenge that can lead to participation:

But I know that there were protests at the lectures sometimes and there were very many who said: 'How can we understand delta and epsilon; help, this is tough!' Most of the students thought it was enormously difficult and tough to understand where all this would lead. I didn't perhaps understand very much myself all the time but I thought it was so very fascinating, very fun, for me it was more like a spur; I want to learn more about this. (Student - Intermediate course, 2003)

The study shows that, besides the possibility of participating in various kinds of activities involving proof, students' learning enhancement is also related to the access students had to various aspects of proof such as the meaning of proof in mathematics, the formal demands of proofs as well as the logical structure of the proofs that are included in the courses. For example, students struggle with questions about what proof 
is. The lack of discussions about the issues led them to feel that they do not know while all the others know what is going on "How do you define a proof? Because we have never been informed about that, so you think: "OK, the rest of the class knows what a proof is"”. An assumption that someone else understands what is going on refers to an identity of non-participation in relation to ownership of meaning (Wenger, 1998).

The metaphor of transparency of artefacts (Lave \& Wenger, 1991) illustrates a dilemma of balancing between using an artefact (proof) and focusing on the artefact with some extended information (importance of proof) (see Hemmi, 2008). The condition of transparency is, in this study, considered both from the teaching and the learning perspective. The analysis revealed several discrepancies between the mathematicians' teaching intentions and expectations, on the one hand, and the students' experiences on the other hand (Hemmi, 2010). For example almost all the students wanted to learn more about proof from the very beginning of their studies while the mathematicians in general expected them not to be interested in proofs. Several mathematicians also avoided proof in order not to frighten the students. Yet, the study shows that leaving something very central aside only because it is expected to be experienced as difficult may not always be the best way to enhance learning. According to the students, the demands in a special course in analysis helped them get insights into the benefits of studying proofs. As Wenger (1998) points out, demanding alignments by a community of practice do not need to mean the lack of negotiability but demanding alignment itself can be a means of sharing ownership of meaning.

The study does not offer recipes about how to deal with proof in different courses, but insights about the complexity of the issue, something important to be aware of and reflect on for both the mathematicians and the students in the practice in order to enhance the joint enterprise, the collective learning of mathematics. 


\section{Case 2: Seeking conceptual understanding of mathematics}

“The mathematics problem” whereby students entering university for mathematics or mathematics-related courses are ill-prepared for the nature of mathematics they will encounter at university level is well documented (e.g., Hawkes and Savage, 2000). School mathematics in the final years is highly procedural in both teaching and learning and few students get the opportunity to reach conceptual understandings of the mathematics they learn (Minards, 2012).

The ESUM project (Engineering Students Understanding Mathematics) ${ }^{3}$ involved the design and operationalization of an innovation in teaching in a first year mathematics module for engineering students in a UK university. The innovation had the aim of enabling students more conceptual understandings of mathematics. A team of four - three experienced mathematics-teacher-researchers and one research officer designed the project and taught, monitored, collected and analysed data, and published results from it. One member was 'the teacher” conducting lectures and tutorials with students. One member was 'the researcher' collecting data from teaching activity. All were involved variously in design of materials and approaches, in monitoring of activity and in analysis of data (Jaworski \& Matthews, 2011b).

Methodologically, the project involved developmental research in which research both studied the practices and processes involved and acted as a tool for development of teaching and learning (Jaworski, 2003; Goodchild 2008). Through an iterative, cyclic, process, the team designed materials and approaches to teaching; the

\footnotetext{
${ }^{3}$ With financial support from the UK HE STEM programme via The Royal Academy of Engineering. HE STEM supports teaching and learning in Science, Technology, Engineering and Mathematics in Higher Education (Tertiary level).
} 
teacher used the designed materials with students, reflected on their use, often with the rest of the team, and modified teaching practice accordingly.

The innovation aimed to engage students in mathematics in ways which encouraged them to think mathematically (Mason, 1988) and which developed an inquiry stance or inquiry ways of being in practice (Cochran-Smith and Lytle, 1999; Jaworski, 2004). Tasks and teaching approaches were designed to draw students into inquiry in mathematics through which they would engage with mathematical concepts more deeply than at their familiar procedural levels. For example, the following questions were part of a series of tasks designed to engage students in the concept of function:

Consider the function $f(x)=x^{2}+2 x \quad(x$ is real $)$

a) Give an equation of a line that intersects the graph of this function

(i) Twice (ii) Once (iii) Never (Adapted from Pilzer et al. 2003, p. 7)

b) If we have the function $\mathrm{f}(\mathrm{x})=a x^{2}+b x+c$.

What can you say about lines which intersect this function twice?

Students were expected to be familiar with quadratic functions, albeit, perhaps, in procedural ways. They were expected to visualise $f(x)$, sketch its graph and be able to think about what lines would cross it twice, once or never. By writing down equations of possible lines, and asking why are these possible but not others, they would engage (conceptually) with mathematics: be drawn into graphical representations of linear and quadratic functions, relate the functions to each other through inspecting intersecting graphs, and start to consider more general cases of such intersections. Their engagement would require them to consider characteristics of such functions and to relate algebraic and graphical forms.

The inquiry nature of the task can be seen in its invitation to explore relationships at a more general level in part (b), drawing on use of established 
knowledge in part (a). The language of "expected to" and "would" above indicates the design stage of developmental research. Tasks such as this were designed to contribute to the aims of the innovation. They were used in lectures or tutorials (Part (a) was used in a lecture and Part (b) in a tutorial following the lecture). In the lecture the teacher posed the question, gave students five minutes to work on it (circulating, viewing, and listening in to their dialogue) and invited responses from a range of students. Such tasks in a lecture aimed to enculturate students into mathematical engagement and oral response - students were expected to participate overtly and, with encouragement from the teacher, many did offer responses. In the tutorial, students were grouped in fours in a computer laboratory, using graphing software (GeoGebra -http://www.geogebra.org/cms/en/) and expected to use the GeoGebra environment to work investigatively on given tasks (such as (b)) and agree on their findings. The teacher circulated, encouraging and discussing with groups their exploration, thinking and findings. The researcher observed and audio-recorded the activity of lecture and tutorial.

The outcomes of this activity were studied in two ways. The teacher reflected on the activity of the students as they engaged with the task and on her perceptions of outcomes of the task for the students. Teacher and researcher discussed the teacher's reflections, the researcher feeding in from her observations, and periodic meetings of the whole team reviewed the ongoing teaching process. Modifications were made to practice based on these reflections and team discussions.

Teacher and students can be seen as part of a community of mathematical practice in which the practice was the teaching-learning of mathematical concepts. This is somewhat problematic since teacher (teaching) and students (learning) cannot be considered as engaging in the "same" practice. However, conceptualising the practice 
as teaching-learning allows us to circumvent this objection: we think of the whole practice of creating joint participation through which students (and teacher) reify mathematical concepts. Dialogue in engagement contributes to reification of concepts as part of participation. Teacher and students play different, but highly interactive, roles and develop identities through their engagement, use of imagination, and alignment with the norms and expectations in the setting (Wenger, 1998).

The community of mathematical practice transforms into a community of inquiry when inquiry becomes a part of the practice. This happens in several layers relating to the differing roles of participants in the community. Inquiry-based tasks engage students and teacher in inquiry in mathematics; the teacher asks, and encourages students to ask mathematical questions which take them more deeply into the concepts. The teacher engages in inquiry into teaching, asking questions about the joint practice as she reflects on interactions with students and hears the researcher's observations. Researcher and teacher and the others in the team engage in research inquiry in the developmental process. All participants engage in critical alignment: rather than expecting to be told by the teacher, students are encouraged to ask mathematical questions and seek their own way of expressing mathematical ideas; the teacher looks critically at her own practice, with evidence from the research, and seeks to modify it to be more aligned with the aims of the innovation; the research team explores the situation as a whole, collecting and analysing data, seeking outcomes of students’ engagement, and recognising issues. As an example, we quote from the teacher's reflection written after a lecture and following discussion with the researcher:

In the first example [in the lecture] on Tuesday, I asked students to draw a triangle of given dimensions before going on to consider use of sine or cosine rules. In fact two triangles were possible for the given dimensions. This turned out to be a very good question, since different students wanted to approach it in different ways and 
we achieved a discussion across the lecture with students in different parts of the room arguing their approach. (Jaworski \& Matthews, 2011b, p. xx)

A seemingly simple task emerged as valuable in engaging students in asking questions and noticing differences, and in alerting the teacher to the nature of tasks that promote student inquiry. Precious lecture time was given to this discussion, so that other plans had to be modified and the consequences assessed. We see critical alignment in student recognition of alternative ways of seeing a mathematical object and in the teacher's necessary adjustments to facilitate the student dialogue.

A community of inquiry transforms a community of practice to promote development. Through critical alignment students develop their understandings of mathematics, teachers develop their understandings of teaching and the researchers their understandings of research-based developmental practice. Such development is rarely straightforward, however. The development that is sought, through the innovation, is specified through the joint enterprise of engaging with inquiry-based tasks, GeoGebra, small group investigation, dialogue and questioning. The outcomes are hugely dependent on the actions and interactions of the participants in inquiry-based practice. These outcomes do not relate only to the inquiry-based nature of the enterprise: they are influenced by a range of factors in the sociocultural settings of the practice. For example, the students' expectations deriving from their school learning lead to some resistance to learning through exploration; lectures and tutorials are influenced by the physical environment where they take place: inflexible lecture theatre space, pressures of curriculum, assessment, timetables and time itself constrain what is possible for the teacher. Inquiry-based practice has to take into account of all of these factors and work with them to achieve the aims of the enterprise. Such "working-with" can be seen as 
part of an overt process of critical alignment which is the key element of a community of inquiry.

Analysis of data from students provided insights into students' perceptions of their engagement in the module. Two quotations reveal some of these perceptions:

As a group we looked at many different functions using GeoGebra and found that having a visual representation of graphs in front of us gave a better understanding of the functions and how they worked. In this project the ability to be able to see the graphs that were talked about helped us to spot patterns and trends that would have been impossible to spot without the use of GeoGebra.” [Group Report] Understanding maths - that was the point of Geogebra wasn't it? Just because I understand maths better doesn't mean I'll do better in the exam. I have done less past paper practice. (Focus group interview)

The first quotation was written by a group of students in their project report which was assessed. In writing in this way, we suggest, they entered into a repertoire of assessment in which they wrote what they perceived would be likely to gain good marks - a positive appreciation of GeoGebra. Nevertheless, what they write gives some indication of their appreciation of value in using GeoGebra to "spot patterns and trends" in understanding functions. The second quotation came from a focus group interview after the end of the module and its assessment. This was typical of comments about the nature of understanding and its relation to assessment. The fact that the module had an exam at the end was hugely influential on students' overall activity and perceptions. Such comments revealed tensions in the inquiry-based enterprise in relation to the norms of university practice which required an end of module examination. Alignment with these norms contradicted the development of inquiry-based norms.

Thus, although there was evidence of student understanding, and some appreciation of how aspects of the innovation contributed to understanding, the various influences on the practice, and especially the assessment by examination (despite the 
more formative project assessment) proved overwhelming. We conducted an activity theory analysis to gain further insights into these evident contradictions (Jaworski, Robinson, Matthews and Croft, 2012).

\section{Concluding section: Theorising communities in university mathematics and ways forward into research}

In this paper we consider university mathematics learning as a social activity and specifically as participation in communities that share common practices. With this as a theoretical perspective we aimed to gain more insight into the nature of teaching and learning by using the theoretical lenses of the Community of Practice (CoP) (Lave \& Wenger, 1991; Wenger, 1998) and the Community of Inquiry (CoI) (e.g., Goodchild et al., 2013)). To this endeavour we revisited the main theoretical underpinnings of CoP and CoI, we exemplified how these have been used in research in university mathematics education and we discuss in details the implementation of these theoretical constructs in two research cases. In this concluding section we reflect on the ways communities have been theorised in university mathematics education research; we discuss the use and the analytical power of both $\mathrm{CoP}$ and CoI; and, we suggest ways forward in future research.

According to Wenger (1998) the community in a CoP is defined by the practice that gives coherence to this community and identity is formed through the participation in this community. In the research examples we presented we identified a spectrum of different ways in which research sees the community formation and the practices that take place in these communities. Hemmi (2006), for example, sees students standing at the periphery of a community consisting of all the people who are engaged with university mathematics at any level and she states that the mutual engagement in this community includes studying, teaching/explaining, learning and communicating 
mathematics. From this viewpoint students' identities are seen in terms of their participation/non-participation and the interaction between these two. Solomon (2007), however, rather than conceptualising students as legitimate peripheral participants, sees students belonging to multiple communities of practice - including that of the mathematical discipline - and she identifies identities of non-participation and/or marginalisation. Such differences beg further reflection on a positioning of students with respect to mathematical practices. Jaworski and Matthews (2011b) identified conflicts between students' previous experience on procedural learning with summative assessment and the more conceptual learning through inquiry-based activity and formative assessment that was desired by the teacher. Additionally, in this study, it became clear that the interactions between students and teacher were influenced importantly by their identities in differing communities. These studies draw attention to the complexities (and tensions) inherent in teaching-learning practices in university education, particularly the multimembership of students or/and teacher. Although Wenger's model of identity attempts to capture complexity in its definition, "it neglects to explore in detail the nature of identity in multiple, and possibly conflicting, communities of practice” (Solomon, 2007, p. 88). To this already complicated picture we add the negotiation of identities especially students' and teacher's alignment to the community structure and rules. Wenger (1998) argues that negotiability is the process in which members gain control over the meaning and, through this, form their identity. However, the theory of CoP offers little insight into how this negotiation takes place especially in terms of members' alignment to the community rules, and how rules are defined, sustained and developed in the context of CoP. With the introduction of critical alignment and inquiry as a tool for negotiation (of meanings in mathematics and in mathematics teaching) contradiction and tensions can be revealed and addressed 
(Jaworski \& Matthews, 2011b). Reflecting on the studies we reviewed we can see the teaching and learning university mathematics practice as a practice in which teacher and students are initially engaged at the boundary of their own communities (e.g. undergraduate students, researcher mathematicians, mathematics educators, etc.) with joint enterprise the development of mathematical learning. If this joint enterprise involves the maintenance of this community and the establishment of shared rules through the critical alignment and realignment, gradually this community will gain its own status and its own economy of meanings, i.e. the social configuration in which negotiation of meaning takes place (Wenger, 1998). This developmental process that addresses conflicts, reconciling perspectives and seeking of resolutions can be theorized through the CoI lenses.

The developmental process we described above cannot been described by newcomer/old-timer relationships that are interested only in the trajectory towards the centre (Lave and Wenger, 1991), as one of the criticisms to the CoP theory claims (for a critical view on these issues, see Barton \& Tusting, 2005; Hughes, Jewson \& Unwin, 2007). Engeström (2007) argues that the newcomers/old-timer relationship is "a foundationally conservative choice” (pp. 42) that marginalises creativity and novelty. Furthermore, although, Wenger (1998) suggested other types of trajectories, including the inbound trajectory, he did not explain how these trajectories affect or influenced by the community (Kanes \& Lerman, 2008). As we mentioned earlier, in university mathematics practices, the interaction of and the tension between different communities are very important, thus their analysis seeks a theoretical tool that can offer a refined insight and go further than their description. Wenger (1998) suggested the complimentary concept of constellation of practices to describe multiple communities which are somehow connected to a specific community. However, the vague definition 
of constellation challenges the stability its explanatory power (Engeström, 2007). Jaworski et al. (2012) applied activity theory to gain further insights in the contradictions occurred in an inquiry-based lesson for mathematics to engineers.

There are two more criticisms on the CoP theory that we would like to discuss in our reflection: the historicity and the role individuals. Both Lave and Wenger (1991) and Wenger (1998) failed to adopt a historical perspective on the development of the community formation and structures that allows understanding of new patterns of relationships and fluctuation under the influence of rabidly changing external technological and financial conditions (Engeström, 2007). Additionally, the role of the individual in the community is undermined. For example agency is not covered in the CoP theory, namely how self-directed individuals respond and affect the learning environment within which they practice (see more at Hughes, Jewson \& Unwin, 2007). Also, the role of power and the interest are implicit and undervalued in the CoP theory (Kanes and Lerman, 2008).

According to Kanes and Lerman (2008) a view that can assist in the identification of the individual in the social context can be offered by a deeper analysis of the elements that constitute this practice. These elements can be the used tools, the technologies and the discursive practices. In Wenger’s (1998) theory, tools, artefacts, discourses are part of the shared repertoire - in terms of practice - and part of the alignment - in terms of the modes of belonging, but their value is implicitly assumed in the overall structure of the community. However, in university mathematics education both resources (tools, artefacts, technology) and discourses are very important and their understanding is crucial in the understanding of university mathematics based communities. Trajectories, for example in a community, can be seen as discursive formations whereas shifting identity of an individual can be identified through the shifting of discourse. Analysis of 
discursive patterns and their development have the potential to give us more insight in our understanding of the establishment, the maintenance and the development of a CoP in university mathematics (see also the Nardi et al. in the same special issue).

Development and introduction of new resources or alternative use of existing ones (documentation genesis, see also Gueudet et al. in the same special issue) can be seen as the critical alignment of the teacher under the influence of the feedback she gets from the students.

Reflecting on the research affordances $\mathrm{CoP}$ and $\mathrm{CoI}$ can offer, we can say that both suggest useful theoretical lenses through which the teaching and learning of mathematics at university level can be examined. In the steps forward we can see a research that can see communities in university mathematics in their complexity (e.g. multimembership, interaction of communities, boundary practices, brokers); embedded in the overall social context (e.g. technological and financial rapid changes); with distinguished role of individuals (e.g. authority, power, personal interest); and, be shaped for mathematical practices that have their own discursive rules and resources. Finally, we believe that more effort should be put in design for a mathematical learning community of practice that has the potential to develop its own economy of mathematical meanings. 


\section{References}

Abdulwahed, M., Jaworski, B., \& Crawford, A. R. (2012). Innovative approaches to teaching mathematics in higher education: a review and critique. Nordic Studies in Mathematics Education, 17(2), 49-68.

Barton, D. \& Tusting, K. (2005). Beyond communities of practice: Language, power and social context. NY: Cambridge University Press.

Biggs, J. (2003). Teaching for Quality Learning at University ( $2^{\text {nd }}$ edition). Maidenhead: Open University.

Biza, I. (2013). Teaching statistics to engineering students: The experience of a newly appointed lecturer Proceedings of the $8^{\text {th }}$ Conference of European Research in Mathematics Education (CERME) (pp. 2306-2315). Antalya, Turkey: ERME.

Blanton, M. L., \& Stylianou, D. A. (2009). Interpreting a Community of Practice Perspective in Discipline-Specific Professional Development in Higher Education. Innovative Higher Education, 34(2), 79-92. doi: 10.1007/s10755008-9094-8

Burton, L. (2004). Mathematicians as enquirers : learning about learning mathematics. London : Kluwer Academic.

Cochran-Smith, M., \& Lytle, S. L. (1999). Relationships of knowledge and practice: teacher learning in communities. In A. Iran-Nejad \& P. D. Pearson (Eds.), Review of Research in Education (pp. 249-305). Washington: American Educational Research Association.

Engeström, Y. (2007). From communities of practice to mycorrhizae. In J. Hughes, N. Jewson \& L. Unwin (Eds.), Communities of Practice: Critical Perspectives (pp. 41-54). London \& New York: Routledge.

Goodchild, S. (2008). A quest for good research. The mathematics teacher educator as practitioner researcher in a community of inquiry. In B.Jaworski \& T. Wood (Eds.), International Handbook on Mathematics Teacher Education: Vol. 4. The Mathematics Teacher Educator as a Developing Professional. Rotterdam, Holland: Sense Publishers.

Goodchild, S., Jaworski, B., \& Fuglestad, A. B. (2013). Critical alignment in inquirybased practice in developing mathematics teaching. Educational Studies in Mathematics, 84(3), 393-412. 
Hanna, G., \& Barbeau, E. (2008). Proofs as bearers of mathematical knowledge. ZDM, 40(3), 345-353.

Hawkes, T., \& Savage, M., (eds) (2000). Measuring the Mathematics Problem, (London, Engineering Council).

Hemmi, K. (2006). Approaching proof in a community of mathematical practice.

Doctoral thesis (monograph). Stockholm University, Department of Mathematics, Stockholm.

Hemmi, K. (2008). Students' encounter with proof: the condition of transparency. ZDM, 40(3), 413-426. doi: 10.1007/s11858-008-0089-9

Hemmi, K. (2010). Three styles characterising mathematicians’ pedagogical perspectives on proof. Educational Studies in Mathematics, 75(3), 271-291. doi: 10.1007/s10649-010-9256-3

Herzig, A. H. (2002). Where have all the students gone? Participation of doctoral students in authentic mathematical activity as a necessary condition for persistence toward the PH.D. Educational Studies in Mathematics, 50(2), 177212. doi: 10.1023/A:1021126424414

Hughes, J. Jewson, N. \& Unwin, L. (Eds.). (2007). Communities of Practice: Critical Perspectives. London \& New York: Routledge.

Jaworski, B. (2003) Research practice into/influencing mathematics teaching and learning development: towards a theoretical framework based on co-learning partnerships. Educational Studies in Mathematics 54, pp. 249-282

Jaworski, B. (2004). Grappling with complexity: Co-learning in inquiry communities in mathematics teaching development. In M. J. Høines \& A. B. Fuglestad (Eds.), Proceedings of the 28th Conference of the International Group for the Psychology of Mathematics Education (Vol. 1, pp. 17-36). Bergen, Norway.

Jaworski, B. (2008). Building and sustaining inquiry communities in mathematics teaching development: Teachers and didacticians in collaboration. In K. Krainer \& T. Wood (Eds.), International handbook of mathematics teacher education: The mathematics teacher educator as a developing professional (Vol. 3, pp. 335-361). Rotterdam: Sense Publishers.

Jaworski, B., \& Matthews, J. (2011a). How we teach mathematics: Discourses on/in university teaching. In M. Pytlak \& T. Rowland (Eds.), Proceedings of the $7^{\text {th }}$ Conference of European Research in Mathematics Education (CERME) (pp. 2022-2032). Rzeszów, Poland. 
Jaworski, B., \& Matthews, J. (2011b). Developing teaching of mathematics to first year engineering students. Teaching Mathematics and its Applications, 30(4), 178185.

Jaworski, B., Robinson, C., Matthews, J., \& Croft, A.C. (2012). An activity theory analysis of teaching goals versus student epistemological positions. International Journal of Technology in Mathematics Education 19(4), 147-152. Kanes, C., \& Lerman, S. (2008). Analysing Concepts of Community of Practice. In A. Watson \& P. Winbourne (Eds.), New Directions for Situated Cognition in Mathematics Education (pp. 303-328). NY: Springer US.

Lave, J., \& Wenger, E. (1991). Situated learning. Legitimate peripheral participation. New York: Cambridge University Press.

Mason, J. (1988). Learning and Doing Mathematics. London: Macmillan.

Minards, B. (2012). An exploration of high-achieving students' experiences of learning and being examined in A-level mathematics. Unpublished $\mathrm{PhD}$ thesis, University of Birmingham.

Pilzer, S., Robinson, M., Lomen, D., Flath, D., Hughes Hallet, D., Lahme, B., Morris, J., McCallum, W., \& Thrash, J. (2003). ConcepTests to Accompany Calculus, Third Edition. Hoboken NJ: John Wiley \& Son.

Solomon, Y. (2006). Deficit or Difference? The Role of Students' Epistemologies of Mathematics in their Interactions with Proof. Educational Studies in Mathematics, 61(3), 373-393. doi: 10.1007/s10649-006-6927-1

Solomon, Y. (2007). Not belonging? What makes a functional learner identity in undergraduate mathematics? Studies in Higher Education, 32(1), 79-96.

Stenhouse, L. (1984). Evaluating curriculum evaluation. In C. Adelman (Ed.), The politics and ethics of evaluation (pp. 77-86). London: Croom Helm.

Vygotsky, L. S. (1978). Mind and society: The development of higher mental processes. Cambridge, MA: Harvard University Press.

Weber, K. (2002). Beyond proving and explaining: Proofs that justify the use of definitions and axiomatic structures and proofs that illustrate technique. For the Learning of Mathematics, 22(3), 14-17.

Wells, G. (1999). Dialogic inquiry: Toward a sociocultural practice and theory of education. Cambridge: Cambridge University Press.

Wenger, E. (1998). Communities of practice: Learning, meaning and identity. Cambridge, UK: Cambridge University Press. 